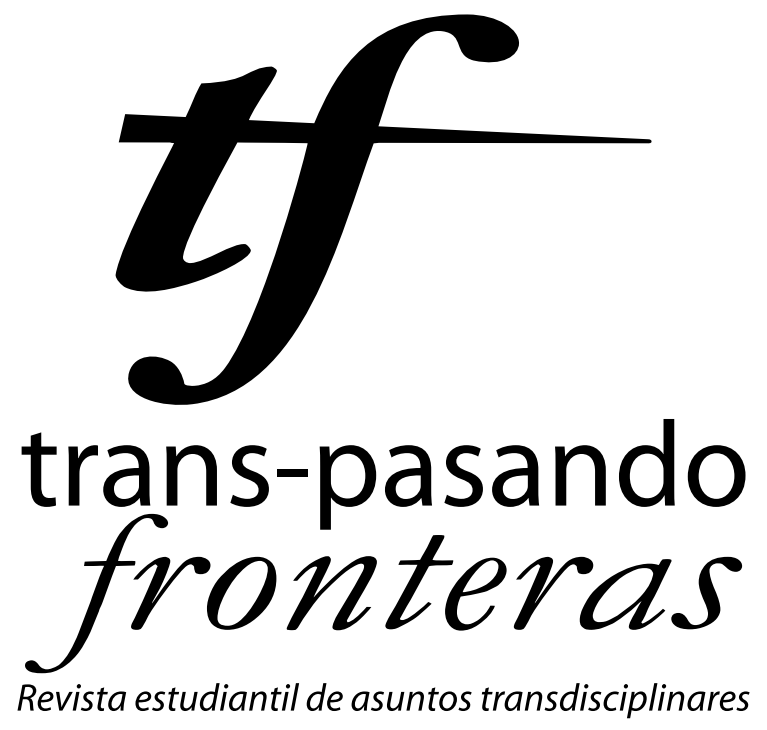

Una publicación de

Estudios

Interdisciplinarios

Jurídicos, Sociales

000 y Humanistas

ICESS

FACULTAD DE

DERECHO Y CIENCIAS

SOCIALES

然 UNIVERSIDAD 


\title{
Sobre llovido, mojado: ahora los (neo) populismos. Problematización desde la Norpatagonia Argentina (NEUQUÉN 1960/2000)
}

\author{
Mónica Viviana Bertoglio** \\ (monicavbertoglio@gmail.com)
}

\author{
Mario Arias Bucciarelli*** \\ (ariasbucciarelli@gmail.com)
}

Artículo de revisión recibido el 28/07/2013 y aprobado el 03/11/2013.

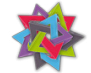

Como citar este artículo:

BERTOGLIO, Mónica Viviana y Mario Arias Bucciarelli (2013). "Sobre llovido, mojado: ahora los (neo) populismos. Problematización desde la Norpatagonia Argentina (NEUQUÉN 1960/2000)”. En: Trans-pasando Fronteras, Núm. 4, pp. 93-112. Cali, Colombia: Centro de Estudios Interdisciplinarios, Jurídicos, Sociales y Humanistas (CIES), Facultad de Derecho y Ciencias sociales, Universidad Icesi.
\end{abstract}

\section{Resumen}

A la controvertida y equívoca trayectoria conceptual del fenómeno populista se ha sumando la del (neo) populismo, tanto para dar cuenta de experiencias políticas en la década de 1990, como para

* Democracia y democratización en un espacio subnacional. Actores, discursos y prácticas en el sistema político neuquino. Director Mario Arias Bucciarelli.

** Profesora en Historia y Especialista en Historia Regional. Desempeñó la docencia en carácter de adscripta a la cátedra Historia Argentina para la carrera de Profesorado y Licenciatura en Geografía y desarrolla sus tareas de investigación como integrante del Grupo de Historia Política del Cehepyc (Centro de Estudios Históricos de Estado, Política y Cultura) con sede en Universidad Nacional del Comahue, Argentina.

*** Profesor en Historia, de la Facultad de Humanidades, UNCo. Doctorado en Historia de la Universidad Nacional del Centro de la Provincia de Buenos Aires, Tandil. Licenciado en Historia de la Universidad Nacional del Comahue, Argentina con Maestría en Ciencias Sociales de la Universidad de la Frontera en Temuco, Chile. 
caracterizar en el presente modalidades de ejercicio del poder materializadas en diversos gobiernos latinoamericanos. En este marco, el objetivo del presente artículo es combinar algunas de estas conceptualizaciones y disputas teóricas con el examen empírico en un ámbito subnacional (Neuquén, norpatagonia argentina), hegemonizado -desde 1963- por el Movimiento Popular Neuquino (MPN). Este partido político ha sido evaluado por la bibliografía como un caso claro de populismo.

\section{Palabras claves:}

Populismo, Neopopulismo, Historia política Norpatagonia, Argentina, MPN.

\section{Introducción}

La apelación en el título a un proverbial apotegma popular trasunta, en cierto modo, lo que subyace en la reflexión propuesta. Si llueve sobre mojado, las implicancias del "aguacero" en nada cambian las condiciones previas, no tienen efecto sustancial, ni implican significativas innovaciones; es más, pueden empeorar la situación.

El populismo, fenómeno ampliamente debatido en la sociología y la ciencia política latinoamericana desde mediados del siglo XX, presenta una extensa y controvertida historia traducida en una vasta producción bibliográfica que sigue suscitando profusas interpretaciones, reinterpretaciones y polémicas ${ }^{1}$. Con fuerte presencia en el debate en las décadas de 1960 y 1970, su exploración es reinstalada bajo la apelación al (neo) populismo en la década de 1990 y reaparece en la actualidad para caracterizar modalidades de ejercicio del poder materializadas en diversos gobiernos de la Región.

Este "estiramiento conceptual", aunque reaviva las polémicas y profundiza la polisemia que desde su origen rodea al término, también incorpora nuevas miradas y perspectivas de indagación que lo alejan de los presupuestos peyorativos con los que tradicionalmente se lo ha caracterizado. En este sentido comienza a ser valorado en su dimensión participativa, en su contribución al proceso de profundización de la democracia y esencialmente en la complejización de la relación líder-masa, presente en todos los postulados en torno al populismo histórico y las nuevas versiones (neo) po-

1 Pretender citar autores resulta un ejercicio inasequible habida cuenta de la vasta producción bibliográfica. Todos los textos aquí utilizados, de una u otra manera, incluyen un "estado de la cuestión" al que remitimos.

2 En su propuesta de avanzar en la política comparada, el autor italiano advierte que uno de los inconvenientes en la universalización de los conceptos puede derivar en la ambigüedad e imprecisión ya que puede conducir a la eliminación de la identidad y las fronteras de su propio contenido. (Sartori, 1970). 
pulistas, con sus variantes. Con este reposicionamiento, otras disciplinas (la antropología, la historia, la filosofía y la teoría política), con renovados enfoques y abordajes teóricos, proporcionan innovadores desafíos y puntos de referencia que -invariablemente controversiales- enriquecen las posibilidades de exploración.

Más globalmente, en la re visita a un fenómeno siempre problemático, resulta imprescindible sopesar los recurrentes y fructíferos aportes de Ernesto Laclau ${ }^{3}$ en torno al populismo como "articulación hegemónica" y a partir del impacto que su Razón Populista instala en el debate académico y político, todas las reelaboraciones y/o refutaciones que ha generado y genera. (Laclau, 2005).

Entre los ejes de la cuestión, al presente resulta pertinente asumir que la noción de discurso refiere no solamente a lo lingüístico en el sentido del habla o de la palabra escrita, sino a toda relación de significación ${ }^{4}$. De este modo, se admite dialécticamente que el campo de lo discursivo se superpone con el de las relaciones sociales y que éstas son tales porque tienen y producen sentidos. (Lesgart y Souroujon, 2008). Así perfilados, concebir las relaciones sociales como discursivas, transcendiendo la noción puramente gramatical del discurso y sus implicancias materiales y simbólicas, pueden asumirse y analizarse como una dimensión explícitamente identificable y articulable con objeto de estudio en cuestión.

Las nuevas miradas, a su vez, habilitan reconocer al populismo como una categoría idónea para la interpretación de procesos que se manifiestan en una diversidad de contextos. Descartando las explicaciones que lo ligan a una circunscripta fase del desarrollo económico o una base social específica, pueden articularse determinadas características que trascienden los distintos períodos históricos y los diversos espacios nacionales. ${ }^{5} \mathrm{El}$

3 Ya desde su liminar libro Política e ideología en la teoría marxista (1978), Ernesto Laclau emerge como uno de los intelectuales que ha instalado en la agenda académica internacional al populismo no sólo como un fenómeno válido de analizar, sino que ha buscado enfoques alternativos al concepto y/o a los términos en lo que se venía reflexionando. Con todo y reconociendo sus invalorables aportes, mantenemos distancia crítica frente a -para decirlo en pocas palabras-: 1) el riesgo tendencial al "reduccionismo de lo social a lo discursivo" y 2) la posible indeterminación en la que puede derivar el conceptuar al populismo no como uno de los tantos modos de construir lo político, sino como "la forma de la politicidad en general".

4 Sobre esta perspectiva resultan esclarecedoras los argumentos y conceptualizaciones, que entre otros brindan Foucault, 1987; Fairclough, 1995; Van Dijk, 1999 y Thompson y Collins, 200.

5 "Buena parte de la incomprensión del populismo latinoamericano y de las discusiones al respecto se origina 
presupuesto que guía las opciones seleccionadas responde a la necesidad de buscar una explicación que dé cuenta de la dinámica política latinoamericana, alejándose tanto de las teorizaciones basadas en la contrastación con el modelo clásico de desarrollo capitalista europeo y cierta estilización ahistórica -que ha sido refutada en la materialización efectiva- del paradigma republicano liberal; como de los análisis centrados en la supuesta ininteligibilidad y/o "excepcionalidad" de las experiencias políticas de los países periféricos. Todo ello a los efectos de avanzar en la línea que prioriza la reflexión densa en torno a las imbricaciones entre sociedad y Estado en el marco del capitalismo dependiente, tanto para espacios nacionales como subnacionales. Tal constatación viabiliza la pertinencia de su utilización para un caso provincial.

Articulando las enunciaciones precedentes, con el examen empírico en un ámbito subnacional (Neuquén) ${ }^{6}$; el presente artículo se propone el abordaje del Movimiento Popular Neuquino $(\mathrm{MPN})^{7}$, entramado partidario que es caracterizado por la bibliografía existente dentro de los parámetros puestos en discusión ${ }^{8}$.

Como núcleos problemáticos a dilucidar -de las tantas dimensiones que el objeto de es-

en la propensión de los autores a reducir un fenómeno complejo a uno de sus elementos aislados: 'las políticas de distribución de ingresos', 'la heteronomía del movimiento obrero', 'la adhesión a las masas marginales', 'el discurso político', 'la promoción industrial', etc”; en Vilas, Carlos (comp). (1995). La democratización fundamental. El populismo en América Latina, México, CONACULTA, p.38..

6 Se trata de una provincia argentina localizada en el oeste de la norpatagonia.

7 El partido surge en 1961 en el marco de la proscripción del peronismo con figuras que habían ocupado cargos públicos en el ex-Territorio, fundamentalmente del interior provincial, y entre los que se destaca la familia Sapag. La nueva expresión política triunfa en las elecciones de 1962 -luego anuladas- y a partir de 1963 convalida su representatividad en todas las instancias electorales de las que participa. A partir de $1991 \mathrm{el} \mathrm{MPN}$ se divide en dos líneas identificadas con las figuras de Felipe Sapag ("sapagismo") y Jorge Sobisch (“sobichismo") respectivamente. Avanzado el 2000 se asiste a un intento por recuperar la identidad originaria en la nueva estructuración emepenista que está gobernando la Provincia. Sobre el proceso político neuquino, véase: Favaro, Orietta y Arias Bucciarelli, Mario. (1995). "Elecciones y crisis en un espacio provincial. El MPN ¿ruptura o continuidad de una forma de hacer política?", en Realidad Económica, No 135, Buenos Aires, pp 103-117, y Favaro, Orietta y Iuorno, Graciela (Eds). (2010), El 'arcón' de la Historia Reciente en la Norpatagonia argentina, Buenos Aires, Biblos.

8 Al respecto pueden mencionarse, entre muchos otros, Palermo, Vicente. (1988). Neuquén: la creación de una sociedad. Buenos Aires, CEAL, No 212; De Rosas, Liliana. (1996). Neuquén Vota. El misterio del Sapagismo, Buenos Aires, Macchi; Favaro, Orietta (Comp). (1999). Neuquén. La construcción de un orden estatal, Neuquén, Cehepyc/UNCo; Favaro, Orietta y Arias Bucciarelli, Mario. (2001). "Reflexiones en torno a una experiencia populista provincial. Neuquén (Argentina) 1960-1990”; en Nueva Sociedad, Caracas, 172, marzo-abril, pp54-64; Rafart, Gabriel. (2009). "Las 'partes' del Movimiento Popular Neuquino", en Revista de la Facultad, General Roca, No 15, pp 93-113. 
tudio posibilita- se seleccionan algunos tópicos, en esta oportunidad, "la visión dicotómica del espacio social" (Biglieri, 2008:109-132), anclados en tres momentos del sistema político provincial. Mediante el análisis de las estrategias y operaciones discursivas del MPN, en las diferentes coyunturas se ponderan y analizan las nociones puestas en juego y los significantes claves que posibilitan esclarecer la conformación y reproducción de identidades en el campo político/cultural de referencia.

Ahora bien, para aproximarse al estudio del espacio neuquino debe advertirse que se trata de un área geográfica que, a diferencia de las otras provincias argentinas, se configura tardíamente y con ciertas particularidades. Tal circunstancia se verifica tanto en su incorporación al sistema federal (conversión de territorio nacional a provincia) ${ }^{9}$ y en la valorización de sus recursos naturales (definición del perfil energético explorador ${ }^{10}$ como en la vigencia - a cinco años de obtenida la autonomía institucional- de un entramado partidario que hegemoniza su sistema político. ${ }^{11}$

\section{Populismos tradicionales y (neo) populismos. Sucintas exploraciones}

Sobre los populismos tradicionales es posible afirmar que el debate adquiere una fuerte presencia en el ámbito académico desde la segunda guerra mundial hasta mediados

9 Es necesario recordar que Neuquén entre 1884 y 1955/1958 reviste la condición de territorio nacional y en este orden constituye una entidad jurídica que a diferencia de las tradicionales catorce provincias argentinas, configura una circunscripción espacial carente de autonomía y con directa dependencia del poder central.

10 Recién a mediados de los años 1970, pero con efectos visibles en los ochenta, la explotación de hidrocarburos y la construcción de complejos hidroeléctricos contribuyen a definir el perfil energético exportador; el consiguiente cobro de regalías, la explosión demográfica y una dinámica reproductiva que se sostiene en la demanda y las inversiones del Estado nacional y sus entes de carácter empresario, la expansión del gasto público provincial, la industria de la construcción y la ampliación consecuente de los servicios Hasta esa fecha, la principal fuente de ingresos lo constituyen los fondos nacionales -coparticipación federal de impuestos, aportes no reintegrables, créditos para obras públicas, partidas especiales- ya que el espacio de referencia se sustentaba en torno a las actividades productivas desplegadas en la etapa territoriana: ganadería en el área cordillerana, minería en el centro norte, agricultura bajo riego y explotación de petróleo en el vértice oriental y funciones ligadas a la ampliación del comercio y la intermediación. En ambas fases hay que examinar que la apropiación y distribución de estos recursos no proviene de procesos productivos endógenos. Para una interpretación global del desarrollo socioeconómico, véase Arias Bucciarelli, Mario. (2007/2008). "Discutiendo interpretaciones. El impacto del “desarrollismo" en el espacio neuquino"; en Revista de Historia, No 11, pp 115-130.

11 Sobre esta caracterización y conceptualización, véase Favaro, Orietta y Arias Bucciarelli, Mario. (1999). "El sistema político neuquino. Vocación hegemónica y política faccional en el partido gobernante", en Favaro, Orietta (Comp). Neuquén la construcción de un orden estatal, Neuquén, Cehepyc/UNCo, pp 253-276. 
de los años setenta, en una reflexión muy vinculada a las escuelas de pensamiento sociológico de inspiración norteamericana ${ }^{12}$. Los aportes, en términos generales, no superan las visiones negativas sobre el fenómeno que es examinado en función de atributos tales como "anormalidad", "desviación” o "manipulación""13. La carga de negatividad que reviste el término está vinculada a dos razones concurrentes. Por una parte deviene de la reducción de esta categoría a un conjunto de relaciones entre el líder y la masa ${ }^{14}$; articuladas a través de una cadena de discursos, liderazgos carismáticos y clases populares manipuladas para fines de control del poder. Por otra, se asienta en una visión sesgada del sentido histórico y el carácter peculiar del fenómeno, atribuible a una lectura eurocéntrica de la experiencia latinoamericana (Quijano, 1998). Con diferentes matices y respondiendo a enfoques teóricos e ideológicos de diverso signo, se examina al populismo como una desviación del proceso histórico: "en tanto vastos sectores de la población son englobados en la categoría de masas, es decir, son percibidos como objetos de la historia -en ocasiones como sus beneficiarios privilegiados-pero no como sujetos" (Zubillaga, 1995:180).

Sin abandonar ciertos rasgos descalificatorios, su exploración es reinstalada bajo la apelación al (neo) populismo en la década de 1990. Esta preocupación deviene por

12 Referentes obligados de este debate, se pueden considerar, Germani, Gino. (1962). Política y sociedad en una época de transición, Buenos Aires, Paidos; Di Tella, Torcuato. (1965). "Populismo y reforma en América Latina”, en Desarrollo Económico, vol 4, No 16, pp 391-425, Weffort, Francisco, “Clases populares y desarrollo social (contribución al estudio del populismo), en Weffort, Francisco y Quijano, Aníbal, Populismo, marginalidad y dependencia, San José, Educa, 1973, pp 17-169; Córdova, Arnaldo. (1979). La ideología de la revolución mexicana, México, Siglo XXI, referenciadas en el funcionalismo; aunque también perspectivas politológicas e históricas más recientes, Murmis, Miguel y Portantiero, Juan Carlos. (1971). Estudios sobre el origen del peronismo, Buenos Aires, Siglo XXI; O’Donnnel, Guillermo. (1982). El Estado Burocrático Autoritario .Triunfos, derrotas y crisis, Buenos Aires, Editorial de Belgrano, y De Ipola, Emilio. (1983), Ideología y discurso populista, Buenos Aires, Folios.

13 Ejemplos siempre analizados de estas experiencias son los gobiernos de Lázaro Cárdenas en México, Getulio Vargas en Brasil, Jacobo Arbenz Guzmán en Guatemala, Víctor Paz Estensoro en Bolivia, Juan Domingo Perón en Argentina y José María Velazco Ibarra en Ecuador.

14 Si bien somos conscientes que el concepto de masa reconoce una rica historia traducida en los debates presente en la sociología, la psicología social y la antropología; no es objeto del presente artículo explayarse sobre el mismo, en este sentido solo aclaramos que se hace referencia a la concepción más tradicional definida por el sociólogo francés Gustave Le Bon, es decir, una "agrupación humana con rasgos de pérdida de control racional", "contagio emocional", "sentimiento de omnipotencia" y "anonimato para el individuo" (Le Bon, 2000). 
la necesidad para dar cuenta del apoyo popular que reciben regímenes políticos que aplican estrategias neoliberales -asociadas al Conceso de Washington- y las nuevas formas de liderazgo en el marco de la crisis de representación, el descrédito de la política y la expansión del pensamiento posmoderno ${ }^{15}$. Este conjunto de presidentes habrían logrado con sus discursos, estilos y estrategias particulares adecuarse al contexto de la globalización; desmantelando la estructuras de poder asentadas durante el proceso de industrialización y los beneficios y derechos garantizados en la versión latinoamericana del welfare state. Sin perder apoyo popular y ejerciendo un fuerte liderazgo ${ }^{16}$, irrumpieron como los mayores defensores de la libertad económica, el ingreso del capital extranjero, la apertura de los mercados y la aceptación de las reformas impuestas por los organismos financieros internacionales. Aunque admitimos su existencia en el debate, adherimos a la posición de quienes refutan tal elasticidad. En este sentido, compartimos las argumentaciones y refutaciones que Carlos Vilas -en un esclarecedor y rigoroso artículo- visualiza "este estiramiento conceptual como producto de una mala caracterización del populismo, carente de rigor metodológico y revelador de cierta confusión analítica respecto del fenómeno a considerar y de los escenarios más amplios que lo enmarcan" (Vilas, 2003:15).

En la transición del milenio, reaparece el (neo) populismo, ahora para caracterizar modalidades de ejercicio del poder materializadas en diversos gobiernos latinoamericanos ${ }^{17}$ que expresan originales y/o aggiornadas formas de entender e instrumentar la política y lo político en el contexto del siglo $\mathrm{XXI}^{18}$. Con mode-

15 Sin pretender exhaustividad, Novaro, Marcos. (1996). "Los populismos latinoamericanos transfigurados", en Nueva Sociedad, No 144, pp 90-103; Machinnon, Moira. y Petrone, Mario (Comps). (1998), Populismo y neopopulismo en América Latina. El problema de la cenicienta. Buenos Aires, Eudeba, pp 13-56; Taguieff, Pierre André. (1996). "Las ciencias políticas frente al populismo: de un espejismo conceptual a un problema real”, en Adler, Frank. et al. Populismo posmoderno, Buenos Aires, Universidad Nacional de Quilmes, pp 29-79; Barros, Sebastián. (2006). "Inclusión radical y conflicto en la constitución del pueblo populista", en CONfines, No 2/3, pp 65-73.

16 Albert Fujimori en Perú, Carlos Salinas de Gortari en México, Fernando Collor de Melo en Brasil, Carlos Saúl Menem en Argentina y Abdalá Bucaram en Ecuador.

17 Hugo Chávez en Venezuela, Rafael Corea en Perú, Evo Morales en Bolivia, Fernando Lugo en Paraguay, y Néstor Kirchner y Cristina Fernández en Argentina.

18 Entre la abundante producción, para una puesta actualizada de los debates, remitimos al dossier "Populismo y Democracia”; en Revista de Ciencias Sociales, segunda época, Quilmes, No 17, 2010. 
los heterodoxos de representación -que responden a diferentes condiciones sociohistóricas y escenarios territoriales específicos-; estos nuevos líderes expresan el cambio en el clima de época que atraviesa América Latina y el mundo. Con matices, en algunos casos muy marcados, un discurso rupturista (en disímiles grados de radicalidad); todos se manifiestan contra el neoliberalismo y sus efectos, apelan al mercado interno, expanden derechos y reposicionan la política; procesando en el antagonismo social, básicamente las demandas de los sectores menos privilegiados. $\mathrm{Al}$ respecto condensa Roberto Follari:

Los nuevos, a los que llamaremos 'neopopulismos' en relación al diferente momento histórico que los recorta, mantienen el liderazgo personalista, la apelación a la 'plebs', el antagonismo hacia los otros partidos y la democracia liberal, la defensa de lo nacional, la tendencia a identificarse con el pais en su conjunto. (Follari, 2010:103-104)

\section{Identidades en el campo político-cultural neuquino.}

Como se adelantó en el ámbito subnacional analizado, el sistema político puede pensarse a partir de la "articulación hegemónica" que recrea el movimiento popular; neuquino. En este orden de enunciaciones y optando por la variable "división dicotómica del espacio social", se ejemplifican las tres coyunturas en el marco del debate viejos y nuevos populismos.

La prolongada condición territoriana en el espacio de referencia, prefigura ciertos rasgos que están presentes en el primer discurso del gobernador Felipe Sapag ${ }^{19}$, quien en 1963, expresa

\footnotetext{
“durante sesenta años los neuquinos, extranjeros en su propia patria, sin derecho cívico ni representantes en el Congreso, quedamos postergados del concierto nacional. La república está en deuda con nuestra provincia, que le ha suministrado por largos años, y sigue haciéndolo, ahorro en divisas por abastecimiento de petróleo, gas y materias primas exportables como lana, cueros, frutas y minerales. No ha recibido a cambio ninguna de las obras fundamenta-
}

19 Gobernador entre 1963/1966; 1970/1972, 1973/1976; 1983/1987; 1995/1999. 
les para su desarrollo; sólo de vivir pobre en una tierra rica” ${ }^{20}$

\title{
La disputa en cuanto a la explotación de los recursos naturales y su debida compensación en
} forma de regalías ${ }^{21}$, es una constante en estos discursos, al igual que la industrialización de los recursos en origen y la financiación de planes de infraestructura que atiendan las demandas de una creciente población ${ }^{22}$. Así, en una Conferencia de Gobernadores Patagónicos, Sapag expresa que

\begin{abstract}
"no pretendemos que la Patagonia fije objetivos nacionales, pero no aceptamos seguir siendo una colonia, de la que sólo se extraen sus recursos. Nos sentimos relegados y olvidados por la patria que amamos, pero que nos mira con indiferencia. El federalismo argentino pareciera agotarse en su antiguo molde: el centralismo. El árbol secular pide savia nueva y estamos en la tarea de vigorizar el federalismo ahora que, por fin, somos provincias con todos los derechos, inclusive el de elegir a nuestro Presidente de la nación y demás autoridades lo cual, hasta ayer, cuando éramos territorios nacionales, nos era negado". (Sapag, 1994:60).
\end{abstract}

20 Sobre el ideario político de Felipe Sapag véase: Bertoglio, Mónica. (2012). "Pensamiento político de Felipe Sapag en los inicios del Movimiento Popular Neuquino.”, en Actas de las VI Jornadas de Historia Regional del Neuquén, Junín de los Andes, JEHN.

21 La regalía es la apropiación de la renta hidrocarburíferos por parte de la provincia poseedora del recurso. Consiste en un canon o tributo que devengan las empresas encardas de su explotación. Hasta la década de 1990, se trataba de YPF (Yacimientos Petrolíferos Fiscales), Gas del Estado e HIDRONOR (Hidroeléctrica Norpatagónica), entes estatales de carácter empresarios encargados de la exploración, explotación, construcciones de centrales y comercialización de los recursos energéticos asentados en los caudalosos ríos y productivos yacimientos de la cuenca neuquina. Tradicionalmente las regalías por petróleo y gas, variaban entre un $12 \%$ a un $15 \%$ y las provenientes de las centrales hidroeléctricas, entre un 5\% inicial a un 12\% durante la década de 1980. Luego de la privatización de estas empresas públicas nacionales, la recaudación proviene de una multiplicidad de compañías privadas a las que se les concesionó el aprovechamiento de los recursos naturales y con quienes se negocian porcentajes diferenciales. En 2012, para el caso de YPF se inicia un proceso de re estatización.

22 Comparando lo sucedido a nivel nacional, los censos permiten observar que Neuquén duplica el ritmo de crecimiento en el periodo 1960-1970 y lo triplica entre 1980-1990. De este modo, en pocos años se pasa de una sociedad relativamente simple, con pocos clivajes, a una configuración compleja; constantes migraciones internas y externas, urbanización acelerada y rápida diferenciación social, con sectores plenamente integrados al proceso de expansión económica y vastos grupos precariamente incorporados a actividades no productivas y a la construcción; a lo que se suma el retraso y la marginalidad de las poblaciones del interior. Los efectos redistributivos instrumentados y los canales de movilidad propios de una cultura de frontera expanden una sociedad que cada vez se vuelve más heterogénea y móvil. Se trata de una población que, si bien electoralmente apoya al partido dominante, mantiene un comportamiento que expone una activa participación en la resolución de los problemas sectoriales. Sobre la dinámica societal neuquina, véase: Favaro, Orietta y Arias Bucciarelli, Mario. (2003). "El ciudadano corrido de la política. Protestas y acciones en la preservación de los derechos a la inclusión”; en Boletín Americanista, Barcelona No 53, pp 45-57. 
La recurrencia a la misma modalidad de interpelación, se mantiene y reafirma en la década de 1980. Al respecto, el gobernador Pedro Salvatori ${ }^{23}$ afirma

\begin{abstract}
"fuimos solidarios desde el primer momento con la decisión de renovar las ideas, las políticas que nos estaban llevando al desastre. Estuvimos de acuerdo en que habia que modernizar el Estado, transformar las estructuras económicas, ponernos al día con los vertiginosos cambios que estaban sucediendo en el mundo. Apoyamos. Redujimos gastos. Hicimos el ajuste. Pero pasaron semanas y pasaron los meses, y cada día aparecía más claro, el Neuquén seguía y sigue siendo una rentable colonia interna al servicio del Estado central, ;No del País! Y esto es lo que hoy vengo a decirle a todo el pueblo del Neuquén, hasta cuándo, neuquinos! Nuestra paciencia se está agotando... Esta no es una provincia pobre, es una provincia saqueada", ${ }^{24}$
\end{abstract}

Frente a lo que considera el saqueo de los recursos naturales por parte del gobierno nacional y su injusta retribución en calidad de regalías, amenaza

"agotados todos los reclamos y todas las instancias negociadoras, dentro del marco de la Constitución y la Ley, siempre y siempre defendiendo nuestros derechos, se hace inexorable cerrar las llaves de gas o de transporte de electricidad, es imprescindible que lo decidamos y hagamos todos juntos".

En este discurso, que podría englobarse en los dispositivos del populismo tradicional, la construcción del interés general a partir de la articulación no conflictiva de los diferentes intereses particulares se asienta en la definición de un enemigo externo. En la cultura política neuquina se trata del Estado nacional y la bandera que se esgrime es el federalismo, elemento fundamental en la estrategia de legitimación. El arraigo de este estilo provincialista de representación de intereses sociales alcanza un éxito notable en la articulación del sistema político local, logrando trasladar el conflicto interno a la instancia nacional.

A diferencia del "sapagismo", donde las funciones del Estado estaban resumidas

23 Integrante de los equipo técnicos del COPADE (Consejo de Planificación y Acción para el Desarrollo), fue gobernador interino entre 1972/1973 y gobernador electo entre 1987/1991.

24 Honorable Legislatura de la Provincia de Neuquén (en adelante HLPN), "Discurso del Gobernador Pedro Salvatori”, en Diario de Sesiones, XX período legislativo, Neuquén, Tomo I, 1991, p. 5475. 
en la triada interventor-distribucionista-planificador, en la década del noventa, la propuesta del "sobichismo" implico el mayor cuestionamiento a la línea fundadora del MPN y su visión de la Provincia. Para el gobernador Jorge O Sobisch ${ }^{25}$ ello queda claramente explicitado cuando opina

\begin{abstract}
"hemos planteado un reordenamiento integral de las actividades del Estado. Hemos encarado la reforma del Estado como tema central. Tenemos que disminuir el empleo público improductivo y la ocupación disfrazada del estado; cuando disminuye ese empleo, debemos estar generando nuevos puestos de trabajo en el sector privado para no producir costos sociales y desocupación". ${ }^{26}$
\end{abstract}

La recurrente interpelación al sector privado local, nacional e internaciona ${ }^{27}$ refleja la multiplicidad y profundidad de medidas a implementar en el marco de la reforma y modernización del Estado.

Ante este cambio en el modelo de provincia, el "sobichismo" -con la bandera de la reforma y el ajuste- redefine al adversario, que deja de ser externo (Estado nacional) para convertirse en interno; esto es, sectores que se oponen a su modelo excluyente, fundamentalmente los sindicatos estatales, los desocupados y los migrantes. De este modo limita la categoría de "neuquinos" a aquéllos que comparten sus visiones de orden y modernización neoconservadora de la sociedad. ${ }^{28}$ En su diagnóstico revela:

"hacer politica en la Argentina, es un desafio. Politicas y politicos han sido el centro de la crítica social en los últimos años. Esta desilusión plural y angustiosa se expresa en el descreimiento y la desconfianza hacia las instituciones. Es la expresión de un fracaso lento pero persistente: el de un país rico que se

25 Gobernador entre 1991/1995; 1999/2003; 2003/2007; y candidato a presidente de la Republica -junto a Jorge Asís- en la campaña electoral del 2007.

26 HLPN, Discurso del Gobernador Jorge O Sobisch, Diario de Sesiones, XXI período legislativo, Tomo I, 1992, p.21.

27 Jorge Sobisch realiza numerosos viajes al exterior (Latinoamérica y Europa) con la intención de atraer inversiones para grandes proyectos, representado una novedad en cuanto a sus antecesores.

28 Bertoglio, Mónica, "De la "transición a la democracia” al neoliberalismo. El Movimiento Popular Neuquino en la posdictadura". Ponencia presentada en las XIII Jornadas Interescuelas. Departamentos de Historia, Catamarca, Universidad Nacional de Catamarca, agosto de 2011. 
sumerge en la pobreza, ¿es el pueblo argentino el que ha fracaso?, ¿ha fracasado la democracia?, ¿han fracasado los politicos?, ¿tienen razón los políticos que hacen del diagnostico una profesión? [...] pero ¿son los denunciadores inocentes y solo los hacedores los culpables de esta situación?". ${ }^{29}$

En realidad, el programa político de Jorge Sobisch y su concepción de Estado mínimo $^{30}$ apela a delegar las áreas principales que le dan sustento al Estado provincial en manos de actores privados. Sin embargo, la fragmentación y polarización que produce y el intento por destruir una dinámica política singularmente incluyente que durante décadas había ido configurando una matriz "Estado céntrica" en este espacio genera fuertes conflictos, manifestaciones y actos de protesta que tendrán una respuesta represiva por parte del gobierno y alcanzarán trascendencia nacional en el paradigmático asesinato del docente Carlos Fuentealba ${ }^{31}$ en abril de 2007.

Ahora bien, en consonancia con el clima post crisis 2001/2002 desencadenado en Argentina y la disputa interna que nuevamente se instala en el MPN, se lleva a cabo la elección de un gobernador más próximo a los lineamientos originales del entramado provincial. En su discurso inaugural, Jorge Augusto Sapag ${ }^{32}$ llama a la prudencia de los distintos sectores que demandan una mayor intervención del Estado provincial y la redistribución de la riqueza, argumentando las posibilidades que brinda el constante y creciente ingreso por regalías petroleras que potencian en Neuquén el carácter energético exportador. En palabras del gobernador

\section{"algunos dirigentes sindicales han planteado la solicitud de aumento de sueldo y como contrapartida han señalado que van a invitar a sus afiliados a la huel- ga. Ya lo han hecho en Salud, hoy lo hacen en Educación. Yo pienso que aque- llos servicios esenciales que presta el Estado, y mucho más allá del derecho de}

29 HLPN, “Discurso del Gobernador Jorge Omar Sobisch”, en Diario de Sesiones, XXXVI período legislativo, Neuquén, 2007, p. 545.

30 Para una indagación pormenorizada sobre el estilo y las políticas aplicadas en esta etapa véase: Fernando Lizárraga "Vicisitudes del estado mínimo en la norpatagonia argentina (Neuquén, 1999-2007); en Arias Bucciarelli, Mario (editor) Iberoamérica Global, vol 4, número 2, Jerusalén, noviembre, 2011.pp.205-230.

31 Dirigente sindical fallecido como consecuencia de la violenta represión ejecutada en una masiva manifestación de protesta convocada por el gremio docente provincial.

32 Gobernador entre 2007/2011 y 2011/2015. 
huelga que consagran la Constitución Provincial y la Constitución Nacional, ese derecho de huelga tiene que ser ejercido con absoluta seriedad y prudencia. No hay ninguna posibilidad de que la Provincia del Neuquén dé una respuesta positiva a un pedido de aumento salarial y mucho menos, y mucho menos del orden de las magnitudes que se han hablado". ${ }^{33}$

Si bien las demandas de los empleados públicos se mantienen, desde su primera gestión el nuevo gobernador no recurre a la represión violenta de los reclamos, sino que redefine la visión dicotómica del espacio social. En este contexto, el adversario -que sigue siendo interno- pasa a ser, en un sentido restringido, el de los proveedores del Estado ${ }^{34}$, y más en general, algunos medios de comunicación. Al respecto enuncia:

“y opino también que se debe ejercer el derecho de opinión con libertad, obviamente, y también y el derechos de difusión y de libertad de prensa [...] pero es diferente, sobre todo en tempos electorales, cuando se desfigura deliberadamente la verdad, cuando ocurre la censura del silencio o se tergiversan palabras, conceptos hechos, cuando se recurre a la mentira especulativa y destructora". ${ }^{35}$

A diferencia de Jorge Sobisch, el actual gobernador Jorge A Sapag privilegia en el discurso el consenso con los históricos adversarios y la mediación antes que llegar a la confrontación directa, lo que no quiere decir que los distintos sectores hayan abandonado sus reclamos y sus manifestaciones diarias. En este orden de consideraciones, el mandatario provincial evidencia en sus discursos un tono conciliador en sus manifestaciones y acentúa la intervención del Estado provincial en respuestas a las demandas de la sociedad neuquina; esto es posible ya que este espacio se ve nuevamente beneficiado por la demanda energética nacional. A la vez y a diferencia de su antecesor -quien llego a la máxima tensión en su intento por aspirar a la presi-

33 HLPN, "Discurso del Gobernador Jorge Augusto Sapag”, Diario de Sesiones, XXXVIII período legislativo, Neuquén, 2009, p 105.

34 Esta confrontación se evidencia en manifestaciones como: "Nos cansamos del manoseo, nos cansamos de recorrer oficinas y que no sepan explicarnos donde están nuestros expedientes" declaró el Presidente de la Asociación de Proveedores del Estado Neuquino, Néstor Figueroa."; en "Proveedores cortarán el puente en reclamo del pago", Diario La Mañana Neuquén, 24 de Enero de 2012, p 5.

35 HLPN, "Discurso del Gobernador Jorge Augusto Sapag...", pp.109. 
dencia de la República en 2007, compitiendo abiertamente con el partido gobernante a nivel nacional-; Sapag manifiesta que es necesario reconvertir la relación con Nación, rompiendo el aislamiento y abandonando la confrontación para constituir lo que concibe como "federalismo de concertación".

\section{Reflexiones y aportes para la discusión}

Con relación a Neuquén se registran variados trabajos referidos a diferentes aspectos de su pasado territoriano y provincial, sin que exista una categorización general que dé cuenta de su experiencia política. Ello dificulta establecer la relevancia teórica de los avances en las distintas investigaciones en curso y, fundamentalmente, imposibilita determinar criterios válidos para la comparación con otras unidades de análisis.

En este contexto, a partir de un anclaje empírico en la experiencia histórica neuquina, el presente artículo pretende instalar un debate y acercar una serie de reflexiones, aportando elementos que contribuyan a esclarecer y especificar la modalidad de funcionamiento que particulariza la construcción y reproducción del Estado provincial ente 1960 y 2000.

¿Puede englobárselo dentro del fenómeno populista? Los viejos y nuevos debates sobre su conceptualización ¿proporcionan una "caja de herramientas" válidas para cimentar un marco referencial adecuado en el abordaje nuestro caso de estudio? Eventualmente, sí. Empero, siempre es conveniente advertir que esta amalgama de postulados -provenientes de modelos teóricos generalizantes y construidos para dar cuenta de otras realidades- genera desafíos cuando se incorpora la Historia en la investigación. Es decir, la mirada desde la perspectiva disciplinar, induce necesariamente a "historiar" las categorías analíticas para evitar errores basados en extrapolaciones equivocadas cuando se trata de aplicar modelos explicativos a áreas, países o épocas no contempladas por quienes los formularon.

Bajo estos presupuestos, las opciones y articulaciones aquí desarrolladas nos permiten enunciar una serie de reflexiones que aportamos para la discusión. Atendiendo a la prolongada etapa territoriana y la sedimentación de ciertos rasgos provenientes de esa experiencia, sumado a la "interpenetración partido-Estado" que traduce la vigencia por casi cincuenta años del MPN; es posible afirmar que la matriz de oposición al centralismo constituye en este espacio un elemento primordial para comprender la 
conformación y reproducción de las identidades políticas.

Sin embargo, el análisis efectuado en el presente artículo intenta demostrar cómo, en la diacronía, la movilidad de una sociedad compleja en su origen, expectativas y valores también produce transformaciones en las prácticas y los discursos con los que el poder la interpela. Por la dinámica del sistema político y la fuerte tendencia a la personalización del liderazgo, los dirigentes del MPN conservan una relativa autonomía que posibilita reformular posiciones según las circunstancias, sin que ello implique pérdida de legitimidad electoral. En este orden de consideraciones debe tenerse en cuenta no sólo la capacidad del entramado partidario y de sus figuras de validar sus intereses y los del Estado como intereses generales, sino también las serias dificultades del resto de los partidos para institucionalizar su estructura y convocar el consenso de la ciudadanía.

De este modo, el MPN logra presentarse como expresión genuina de los intereses generales de los "neuquinos", garante y protector de los recursos naturales frente un gobierno nacional que extrae sus riquezas y propulsor de un desarrollo global asentado en los propios límites jurisdiccionales. Como ordenador de las prácticas sociales y productor de las representaciones simbólicas, internaliza en la sociedad provincial la certeza en torno a que es una función del Estado procesar y traducir los intereses y las reivindicaciones sociales en políticas públicas.

Con todo, la extendida vigencia de la expresión política provincial no puede explicarse a partir de una visión estática de un modo de desarrollo, ni en la invariabilidad de sus enunciaciones discursivas. A pesar de mantener legitimidad electoral en las diferentes coyunturas, expresa divergencia en la aplicación de sus propuestas económicas y variables modalidades de relación con el poder central, con los componentes de su heterogénea sociedad y, por ende, con su estrategia de interpelación a los ciudadanos provinciales.

Durante el decurso del ciclo expansivo del mercado interno argentino, la explotación de los recursos naturales a través de los entes estatales de carácter empresario y el constante crecimiento demográfico, generaliza el discurso federalista y localista frente al Estado nacional que, si bien reconoce antecedentes en anteriores gestiones, se hace dominante durante la década de 1980. 
Ello permite enunciar un discurso que se asienta en torno a la defensa de los derechos esenciales de la provincia, pone énfasis en la satisfacción de las necesidades básicas de los "neuquinos", y potencia la sensación de cambios rápidos en las condiciones materiales y sociales, recreando en el imaginario colectivo la idea del equilibrio entre todos los sectores y la viabilidad de su participación y progreso dentro de los límites provinciales.

La unidad sin diferencia a partir de la cual se erige el MPN le permite ir construyendo la "identidad neuquina", con postulados ideológicos definidos -la lucha contra el poder central- y propuestas programáticas concretas -negociación ventajosa con los gobiernos nacionales de turno-, que en su conjunto coadyuvan a esclarecer el particular comportamiento del electorado. En la versión "sapagista" incluye a los neuquinos y a los migrantes nacionales y extranjeros, que decidieron establecerse en este espacio, desarrollando las áreas claves de salud, vivienda, educación e infraestructura urbana y vial, potenciando las empresas estatales e integrando el territorio provincial.

A partir de la década de 1990 y en sintonía con las políticas neoliberales impulsadas por el poder central, el "sobichismo" se aleja de los postulados originales del partido, abandonando el carácter intervencionista y planificador del Estado y desmantelando las políticas universales de bienestar social. En consecuencia, apuesta fuertemente al sector privado, a las empresas transnacionales (básicamente petroleras) y a la consolidación de nuevos grupos locales que obtienen múltiples beneficios, y dicotomiza delimitando claramente un enemigo interno: los que se oponen a su estrategia y, más específicamente, los empleados públicos.

En la transición del milenio se observa en el seno del MPN una nueva reformulación tendiente a potenciar la línea interna que -subordinada en los noventa- ambiciona recuperar la mística y los axiomas fundacionales. En este sentido redefine las relaciones con el poder central, ya no adversario indiscutible, y a nivel local, con buena dosis de pragmatismo: polariza el espacio social, redefiniendo en situaciones cambiantes distintos adversarios. Todo esto sin dejar de invocar a los "neuquinos" e intentar procesar en términos políticos las demandas emergentes. Obviamente, se trata de un proceso en curso, un devenir abierto e inconcluso. 


\section{Bibliografía}

ARIAS BUCCIARELLI, Mario. (2007/2008). “Discutiendo interpretaciones. El impacto del 'desarrollismo' en el espacio neuquino”. En Revista de Historia, Neuquén, No 11.

BARROS, Sebastián. (2006). "Inclusión radical y conflicto en la constitución del pueblo populista, CONfines, No 2/3.

BERTOGLIO, Mónica. "De la "transición a la democracia” al neoliberalismo. El Movimiento Popular Neuquino en la posdictadura", Ponencia presentada en las XIII Jornadas Interescuelas. Departamentos de Historia, Catamarca, Universidad Nacional de Catamarca, agosto de 2011.

BERTOGLIO, Mónica. (2012). "Pensamiento político de Felipe Sapag en los inicios del Movimiento Popular Neuquino.”, en Actas de las VI Jornadas de Historia Regional del Neuquén, Junín de los Andes, JEHN.

BIGLIERI, Paula. (2008). "El retorno del pueblo argentino: entre la autorización y la asamblea. Barrios de pie en la emergencia de la era kirchnerista “. En Villa Libre Cuadernos de Estudios Sociales Urbanos, No 2.

CÓRDOVA, Arnaldo. (1979). La ideología de la revolución mexicana, México, Siglo XXI.

DE IPOLA, Emilio. (1983). Ideología y discurso populista, Buenos Aires, Folios.

DE ROSAS, Liliana. (1996). Neuquén Vota. El misterio del Sapagismo, Buenos Aires, Macchi.

DI TELLA, Torcuato. (1965). "Populismo y reforma en América Latina”, en Desarrollo Económico, Vol, No 16.

DIARIO LA MAÑANA NEUQUÉN, 24 de Enero de 2012, p 5.

FAIRCLOUGH, Norman. (1995). “General introduction”. En Critical discourse analysis. The critical study of language. London and New York: Longman.

FAVARO, Orietta y ARIAS BUCCIARELLI, Mario. (1995). "Elecciones y crisis en un espacio provincial. El MPN ¿ruptura o continuidad de una forma de hacer política?. En Realidad Económica, No 135, Buenos Aires.

FAVARO, Orietta (comp). (1999). Neuquén. La construcción de un orden estatal, Neuquén, Cehepyc, UNCo.

FAVARO, Orietta y ARIAS BUCCIARELLI Mario. (2001). "Reflexiones en torno a 
una experiencia populista provincial. Neuquén (Argentina) 1960-1990”. En Nueva Sociedad, No 172, marzo-abril.

FAVARO Orietta y IUORNO Graciela (Eds). (2010). El 'arcón' de la Historia Reciente en la Norpatagonia argentina, Buenos Aires, Biblos.

FOLLARI, Roberto. (2010). La alternativa neopopulista (el reto latinoamericano al republicanismo liberal, Rosario, Homo Sapiens.

FOUCAULT, Michel. (1987). El orden del discurso. Barcelona, Tusquets.

GERMANI, Gino. (1962). Política y sociedad en una época de transición, Buenos Aires, Paidos.

HONORABLE LEGISLATURA DE LA PROVINCIA DE NEUQUÉN, "Discurso del Gobernador Pedro Salvatori”, Diario de Sesiones, XX período legislativo, Neuquén, Tomo I, 1991.

HONORABLE LEGISLATURA DE LA PROVINCIA DE NEUQUÉN, Discurso del Gobernador Jorge O Sobisch, Diario de Sesiones, XXI período legislativo, Tomo I, 1992.

HONORABLE LEGISLATURA DE LA PROVINCIA DE NEUQUÉN, "Discurso del Gobernador Jorge Omar Sobisch", Diario de Sesiones, XXXVI período legislativo, Neuquén, 2007.

HONORABLE LEGISLATURA DE LA PROVINCIA DE NEUQUÉN, "Discurso del Gobernador Jorge Augusto Sapag”, Diario de Sesiones, XXXVII período legislativo, Neuquén, 2008.

HONORABLE LEGISLATURA DE LA PROVINCIA DE NEUQUÉN, “Discurso del Gobernador Jorge Augusto Sapag”, Diario de Sesiones, XXXVIII período legislativo, Neuquén, 2009.

LACLAU, Ernesto. (1978). Política e ideología en la teoría marxista, Madrid, Siglo XXI. LACLAU, Ernesto. (2005). La razón populista, Buenos Aires, FCE.

LESGART, Cecilia y SOUROUJON, Gastón. (2008). "Democracia, política y conflicto. Apuntes teórico-políticos sobre el cambio de clima político-cultural de la última década". En Fernández Arturo y Lesgart Cecilia (Comps.), La democracia en América Latina. Partidos políticos y movimientos sociales, Rosario, Homo Sapiens.

LÍZARRAGA, Fernando. (2011). "Vicisitudes del estado mínimo en la norpatagonia argentina (Neuquén, 1999-2007). En Arias Bucciarelli, Mario (Ed.) Iberoamérica Global, vol 
4, número 2, Jerusalén, noviembre.

MACHINNON, Moira y PETRONE, Mario (Comps). (1998). Populismo y neopopulismo en América Latina. El problema de la cenicienta. Buenos Aires, EUDEBA.

MURMIS, Miguel y PORTANTIERO. Juan Carlos. (1971). Estudios sobre el origen del peronismo, Buenos Aires, Siglo XXI.

NOVARO, Marcos. (1996). "Los populismos latinoamericanos transfigurados”, Nueva Sociedad, Caracas, No 144.

O’DONNEL, Guillermo. (1982). El Estado Burocrático Autoritario. Triunfos, derrotas y crisis, Buenos Aires, Editorial de Belgrano.

PALERMO, Vicente. (1988). Neuquén: la creación de una sociedad. Buenos Aires, CEAL, No 212;

QUIJANO, Aníbal. (1998). "Populismo y fujimorismo". En Burdano de Lara, Felipe (Comp), El fantasma del populismo. Aproximaciones a un tema (siempre) actual, Venezuela, Nueva Sociedad.

RAFART, Gabriel. (2009). “Las 'partes’ del Movimiento Popular Neuquino”, en Revista de la Facultad, General Roca, No 15.

SAPAG, Felipe. (1994). El Desafío, Temuco, Impresos Spring Ltda.

SARTORI, Giovanni. (1970). "Concept Misformation in Comparative Politics”, en:The American Political Science Review, No. 4.

TAGUIEFF, Pierre André. (1996). "Las ciencias políticas frente al populismo: de un espejismo conceptual a un problema real". En Adler, Frank et al. Populismo posmoderno, Buenos Aires, Universidad Nacional de Quilmes.

THOMPSON, Geoff y COLLINS, Heliosa. (2001). "Entrevista con M. A. K. Halliday, Cardiff, julio de 1998”. D.E.L.T.A., 17(1).

VAN DIJK, Teun Adrianus. (Ed.). (1999). Los estudios del discurso. 2 vols. Barcelona: Gedisa.

VILAS, Carlos (Comp). (1995). La democratización fundamental. El populismo en América Latina, México, CONACULTA.

VILAS, Carlos. (2003). “¿Populismo reciclado o neoliberalismo a secas? El mito del ‘neopopulismo' latinoamericano”. En Revista Venezolana de Economía y Ciencias Sociales, Caracas, No 3. 
WEFFORT, Francisco. (1973). "Clases populares y desarrollo social (contribución al estudio del populismo). En Weffort, Francisco y Quijano, Aníbal, Populismo, marginalidad y dependencia, San José, Educa.

ZUBILLAGA, Carlos. (1995). "El batllismo: una experiencia populista". En Vilas, Carlos (Comp): La democratización fundamental. El populismo en América Latina, México, CONACULTA, 1995. 